\title{
AN EVALUATION OF CONFLICTING SHARE OF STAKE HOLDERS' CONTRIBUTION TOWARDS DEVELOPING AN INTEGRATED SUPPLY CHAIN INFRASTRUCTURE FOR FRUITS \& VEGETABLES
}

\author{
* Veena. A \\ ** K. Nagendra Babu
}

\begin{abstract}
Fruits and vegetables traverse from farm to consumer palate. Wholesalers, transporters, commission agents, warehouses and retailers are the common intermediary stakeholders'. Government, semi government bodies, insurance and finance companies, consumer organizations and trade associations are other important stakeholders in fruits and vegetables supply chain management. Seasonal - perishable products like fruits and vegetables are delicate by very nature. Both supply and demand are difficult to predict and more difficult to control. The demand for fruits and vegetables is more concentrated in urban centers that are generally far away from the places that grow fruits and vegetables. Hence, developing integrated supply chain for fruits and vegetables is a challenge. In addition to this, the interests of different stakeholders are isolated. The contribution of different stake holders is not defined. The much needed supply chain infrastructure like all weather roads, special vehicles, pre cooling, washing, waxing, grading, packing and handling facilities, terminal markets, storage and processing facilities, information system and technology can not be developed without mutual cooperation and collaboration among different stake holders. For example, all the stake holders have to participate in information dissemination and management for an effective Market Information System.
\end{abstract}

\section{Introduction}

India is the second largest producer of vegetables in the world (ranks next to China) and accounts for about 14 per cent of the world's production. The total production of fruits and vegetables in the world is around $\mathbf{3 7 0}$ Million Tons (MT). India produces 90.85 MT of vegetables and the total area under vegetable cultivation is around 6.2 million hectares which is about 3 per cent of the total area under cultivation in the country. Among vegetables, potato, tomato, onion, cabbage and cauliflower account for around 60 per cent of the total vegetable production in the country, in terms of quantity.

India ranks first in fruit production in the world with an annual output of $47 \mathrm{MT}$ and accounts for 10 percent of the world's fruit production. There are almost 180 families of fruits that are grown all over the world. Major Indian fruits consist of mango, banana, citrus fruits, apple, guava, papaya, pineapple and grapes. In India just about two per cent of fruits and vegetables (F\&V) grown goes for processing, while over 30 per cent is spoiled due to improper handling and storage'.

* Veena. A, Assistant Professor, MBA Program, PESIT, Bangalore and can be reached at veenaandini@pes.edu

* K. Nagendra Babu, Reader, Dept. of Commerce, Manasa Gangothri, Mysore University, Mysore and can be reached at nagendrababu280@yahoo.co.in 


\section{Integrated Supply Chain Infrastructure}

Supply Chain infrastructure plays an important role in growing, distributing and retailing of fruits and vegetables profitably. Customers would be able to get quality fruits and vegetables at competitive price. Today, supply chain suffers from maximum inefficiency.

Jones and Riley define Supply Chain Management (SCM) as an integrative approach to dealing with the planning and control of the materials flow from suppliers to end- users ${ }^{2}$. According to Fearne, SCM seeks to break down the barriers which exist between each of the links in the supply chain, in order to achieve higher levels of service and to substantially reduce costs. It seeks to achieve a relationship of mutual benefit by defining the organizational structures and contractual relationships between buyer and seller, which up until now have been classified as adversarial ${ }^{3}$. SCM is a modern paradigm for improving competitiveness by coordinating different stakeholders. By promoting coordination among several stakeholders, SCM enables each of them to develop beyond what would be possible for them on their own as individual stake holder with limited resources. Supply chain management connect the participants of a value chain in an efficient network of relationships and tra ssactions that can reduce costs, improve customer service, develo $>$ the organization's knowledge base, increase efficiency within the organization and create barriers to entry for competing organizations $s^{4}$.The nature of customersupplier relationships can be described by several attributes, such as the level of co-operation, the type of information shared among supply chain actors, the time horizon of the relationship, the formality of co-operation and the degree of flexibility ${ }^{5}$. SCM practices today are indeed proactive, cooperative activities that require joint forecasting and planning, information sharing, joint inventory management, and joint control to eliminate wastes throughout the supply chain and enhance customer service for the purpose of obtaining competitive advantage for the supply chain members as well as the supply chain as a whole. A supply chain is a group of businesses linked together. It is one of the important marketing functions. Collaboration has become the Holy Grail in supply chain technology. Supply Chain Collaboration is any kind of joint, coordinated effort between two parties to achieve a common goal. It plays a key role in achieving flexibility and responsiveness.

Collaboration in supply chain helps stakeholders in many ways. Reduction in inventory, reduction in labour cost, improved customer service, better delivery through reduced cycle times, increased speed to market of new products, focus on core competencies, increased public image, strengthened trust and interdependence, increased sharing of information, ideas, and technology, better coordination among stakeholders, and Increased stakeholder value are important benefits of collaboration among different stakeholders of supply chain.

\section{Conflicts and challenges in supply chain infrastructure}

Fruits and vegetable supply chain traditionally been fragmented. Structural change is required to build and maintain supply chain infrastructure. For example, unorganized retailers do not have 'scale of operation' to build their own supply chain. It is necessary to integrate them with ever increasing fraternity of organized retailers as for as supply chain is concerned. This requires a paradigm shift in structural change. Business process reengineering in supply chain is answer to many of these problems.

In order to make supply chain effective, it is necessary to segment different customers. Caterers, hostels, small town unorganized retailer, unorganized retailer in a metro, organized retailer 
and processors of fruits and vegetables cannot be considered as one segment of buyers. In order to make supply chain more effective it is necessary to have different approach to all these stake holders.

Customized logistics is another important immediate requirement to make logistics effective. This reduces the cost, facilitates in maintaining quality of the produce and fulfills the requirement of targeted customers. All fruits and vegetables does not fit into one basket. Nor all cutting edge sellers (retailers, caterers, processors etc.) requirements are same. In this background, it is necessary to customize logistics.

Demand planning for fruits and vegetables is difficult and challenging. Farmers, wholesalers, food manufacturers, retailers all work in silos. Today, demand forecasting is totally absent and the farmers try to push what they produce in to the market. Data integration, financial flow management, supply-demand matching, collaborative forecasting, information sharing, goods movement synchronization through efficient transport scheduling, are very well practiced in high technology industries with immense benefits. These best practices should find their way in to the fruits and vegetable supply chains.

Sourcing has gone strategic in industries. The competitive supply chain management in fruits and vegetables also has to go for strategic sourcing. The cost of procurement, transportation cost. regularity of supply, quality of products, ethical practices of producers, terms and conditions of payment, road connectivity are important factors which influence strategic sourcing. Strategic sourcing is crucial for success of F\&V supply chain in the long run.

In order to keep track of supply chain performance, the supply chain performance measurement has to be carried on a continuous hasis. All the parties involved with supply chain have to be made parties to assess the performance of any supply chain. New bench marks have to be set from time to time to make the supply chain to improve its performance. Supply chain has to evolve beyond the confines of individual stakeholders. Stakeholders cannot work in silos. The biggest challenge to make any supply chain for fruits and vegetables to work better is to make each stakeholder realize their role in supply chain. This is a challenging task mainly because the work of one stakeholder overlaps with another, the work of each stakeholder is not defined, the responsibility of each stakeholder changes with the change of scale of operation and sometimes the stakeholders perceives that their roles are conflicting.

The business to business relationships among different stakeholders make cost sharing and collaborating a challenging task. Who has to share what cost is a big conflicting point in integrating supply chain. Who has to share the cost of construction and maintenance of roads? Who has to pay how much for cold storage? Who has to bear the cost of processing and analyzing information which are useful to farmers and consumers? Who has to bear research and development expenditure and in what ratio? Incompatible organizational cultures make different stakeholders agree for one size solution difficult. Even though answers to these are challenging, there are solutions. For example, Activity Based Costing $(A B C)$ would give answer to many of these questions.

\section{Integrated Fruits and Vegetables Supply Chain Model}

This model is developed by studying the role of different stakeholders in developing integrated supply chain infrastructure. Many of the supply chain tasks are overlapping among different stakeholders. Government has a unique role of fulfilling its social commitment by providing connectivity between 


\section{Integrated Fruits and Vegetables Supply Chain Model}

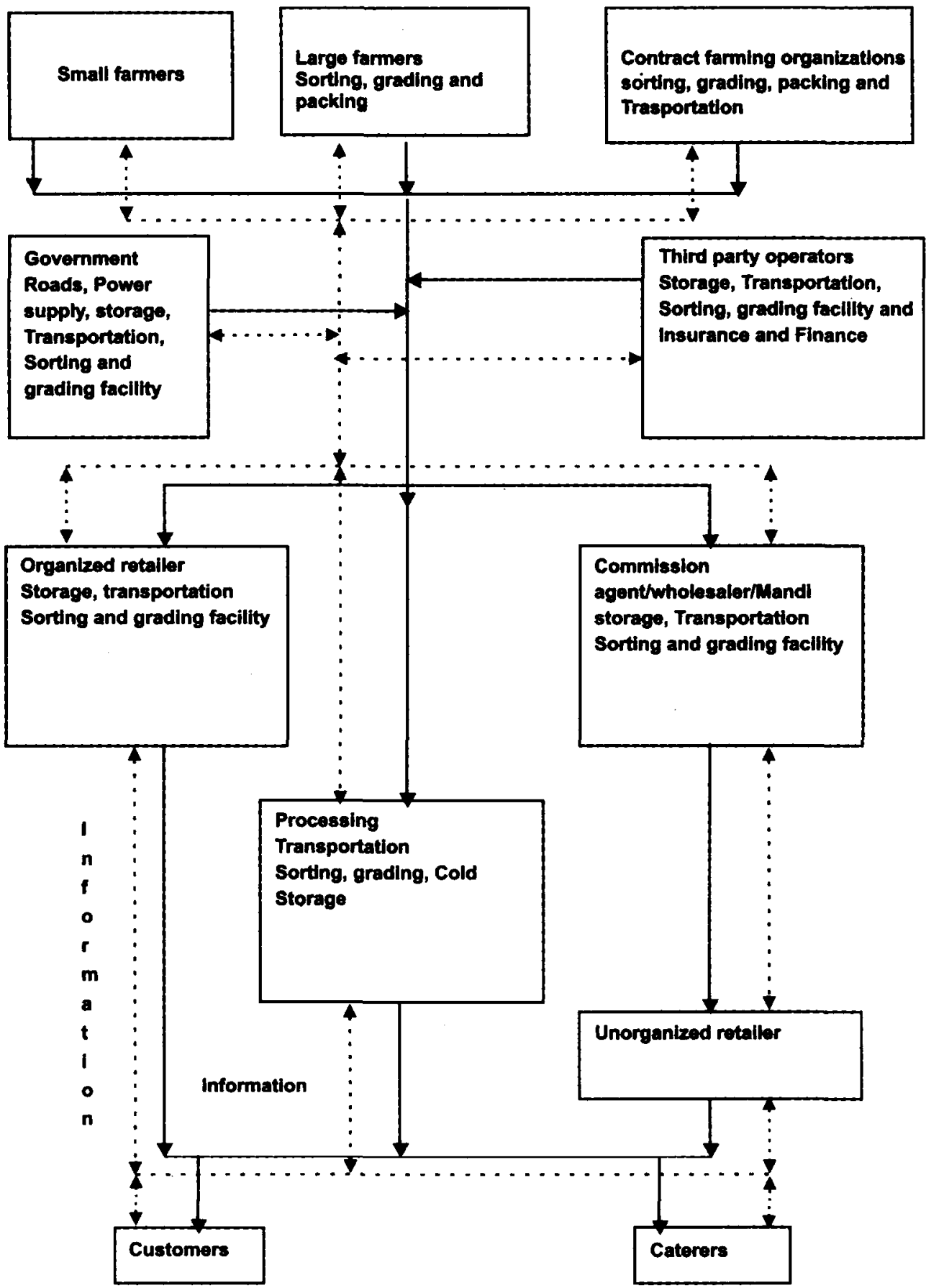

Adarsh Journal of Management Research 
Fruits and Vegetable supply chain clusters are formed with the participation of all stakeholders such as farmers, transporters, cold chain service providers, wholesalers, retailers, financial institutions, and insurance companies. Information sharing is essential for generating the efficiencies. The Internet and mobile communications can also be used to enable information and financial transfer between the stakeholders. All weather roads, special vehicles, pre cooling, washing, waxing, grading, sorting, packing, and handling facilities, terminal markets, storage and processing facilities, information system and technology are important components of supply chain infrastructure. Stateof-the-art infrastructure for transportation, cold chain and processing is critical to ensure high quality and consistent supply of perishable commodities like fruits and vegetables. An estimated 30 per cent of India's farm produce is lost due to poor infrastructure such as insufficient cold storage capacity, unavailability of cold storages in close proximity to farms, poor transportation infrastructure, and etc. ${ }^{6}$

\section{Sorting, Grading and Packing}

Sorting and grading demands expertise, facility and information about market conditions. Packing demands new technologies, materials and facilities. Hence, sorting. grading and packaging demands huge investment on resources, managerial expertise and research and development. Package SKUs and bar Code is another crucial area for collaboration and cooperation. This needs technology compatibility and adaptability among different stakeholders. The information required for sorting and grading on a regular basis has to be shared by all stake holders. Large farmers and contract farming organization can have sorting, grading and packing facilities at their level. Government has to provide sorting, grading and packaging facilities, particularly to facilitate small farmers who cannot have their own facilities. Sorting, grading and packaging can be done at the organized retailer level too. Many organized retailers like Foodworld, Food bazaar, fresh@, and Reliance freșh have their own Centralized Procurement Center for each city, where the products are sorted, graded and packaged. Third party operators can also facilitate sorting, grading and packaging activities in addition to wholesaler performing these activities. Food processing companies procure in large scale and resort to sorting and grading.

\section{Roads}

India lives in villages. This is true in respect of growing fruits and vegetables too. There are more than 6 lakh villages in India. Roads play a key role in connecting farmers and consumer. All weather roads are another important infrastructure required for F\&V supply chain. This is one infrastructure, where Government has to play a key role. Connecting market with the farm is immediate need of the hour. In Indian conditions, building roads is the responsibility of the government. Other stakeholders can also be roped in to maintain road infrastructure. Otherwise roads can be built on BOOT (Build, Own, Operate and Transfer) or BOO (Build, Own and Operate) model by roping in private players. Under BOOT and BOO models too, government has to give some incentives to at least those roads where traffic is commercially not viable.

\section{Transportation}

From farm to palate of consumers F\&V have to traverse a long way. This journey is crucial for maintaining quality of F\&V. This journey is also crucial for avoiding wastage, which is close to 30 per cent of all that we grow. Good transportation system facilitates farmers to get better returns and consumers to get quality products. This refrigerated transportation has to be facilitated by contract farming organizations, Government, third party operators, wholesalers and organized retailers. The companies which process $F \& V$ can have their own refrigerated transportation system. 


\section{Insurance and Finance}

Insurance and finance are two important components of integrated supply chain management, which are to be provided by third party operators. These specialized services are crucial for success of total supply chain. Existing financial and insurance companies can develop exclusive products for fruits and vegetables supply chain.

\section{Cold Storage}

Among all important supply chain infrastructure requirements, cold storage facility demands immediate attention in India. Cold Storages help in extending the shelf life and the period of marketing of fruits and vegetables, avoiding gluts, reducing transport bottlenecks during peak period of production and maintenance of quality produce. Cold Storages help the producers to avoid distress sale and realize better prices in the post harvest season. The consumers are assured of constant supply of quality produce at reasonable price. There are only 5,101 cold storage units in the country with cumulative capacity of 21.7 million tons ${ }^{7}$. Important limitations for efficient utilization of available capacity are lack of quality power supply and cost of power. Energy expenses make up about 28 per cent of the total expenses for Indian cold storages compared to 10 per cent in the West. These factors make setting up cold storages difficult, unviable and uneconomical ${ }^{6}$. In order to improve cold storage facilities, state governments and central government have to ensure quality power supply. Cold chains can save Rs.75,000 crore annually by cutting 30 per cent of wastage of perishable horticultural produce through an integrated cold chain management. For example, proper cold chain system can prolong the life of onion and potato for six months. In order to provide cold storage chains in India, Cold storage task force has been set up by Ministry of agriculture, Government of India and $\mathrm{Cll}^{8}$. Cold chain infrastructure require a huge sum of Rs. 18,000 crore to Rs.20,000 crore investment in the next five years 9. Investment is required to build the cold storage chain, the refrigerated trucks which procure the produce from the farm gate, then pre-cooling chambers, cooled area for sorting and grading the produce, refrigerated trucks for transferring the produce to the markets. The development of this chain requires huge investment in technology, infrastructure and maintenance. Governments have to take lead role in building and maintaining cold storage facilities. Public Private Partnership (PPP) model can help to pump in huge capital and technology required in this sector. This is collective responsibility of governments and private sector. Organized retailers also have scale of operation and financial capacity to build cold storage facility. In Indian context where unorganized retailers continue to play a key role in retailing, at least, in coming many years, it is better, if organized retailers extend their cold storage facilities to unorganized retailers at affordable charges.

\section{Integrated Information System}

Integrated information is another most important F\&V supply chain requirement. It is a challenging task mainly because the information has to move from consumers to farmers and from farmers to consumers in both directions. In addition to this, government, financial institutions, insurance companies, research and development institutions all have a key role in sharing information with all the stakeholders. In addition to sharing information, the available information has to be analyzed to take decisions by different stake holders. Collecting, analyzing and facilitating right decisions is the responsibility of governments, research and development organizations, universities, retailers, wholesalers, financial and insurance companies, warehouses, transport providers and other stake holders. The information management system would help consumers and farmers in different ways. 


\section{Agri Export Zones}

Agri Export Zones (AEZs) attempts to take a comprehensive look at particular produce/products located in a contiguous area for the purpose of developing and sourcing the raw materials, their processing and packaging, finally exporting them. Thus, the entire effort is centered on a cluster approach of identifying the potential products, the geographical region in which these are grown and adopting an end to end approach of integrating the entire process, right from the stage of production till it reaches the market. The government has to help in sourcing for raw materials, the setting up of processing facilities, providing finance at low interest rates and even matching with international buyers. The export zones mooted by the Agricultural and Processed Food Products Export Development Authority (APEDA) to increase international trade in agri-commodities are an attempt to take a holistic approach to encouraging trade in specific commodities located in contiguous areas. For instance, in Tamil Nadu, the AEZs would focus on grapes, mangoes and chikkoo, in Kerala vegetables, in Punjab and Haryana - kino, wheat and rice, Karnataka - vegetables and flowers, Maharashtra - mangoes, grapes and flower, Gujarat - bananas, mango, castor and garlic, and in Uttaranchal - litchi and medicinal plants.

\section{Conclusion}

Integrated supply chain is immediate necessity to meet the requirement of farmers, consumers and different stakeholders. Farmers get better return for the produce and consumers would get quality products at reasonable rates. More than all, this integrated supply chain avoids wastage to a great extent which contributes to economy as a whole in a big way. The wholesalers, retailers too gain from increased performance of supply chain. The financing and insurance companies and storage houses too would get continuous business and contribute for integrated supply chain in big way. Integrated supply chain not only helps to avoid conflicting approach of different stakeholders but facilitates collaboration and coordination among different stakeholders.

\section{REFERENCES}

1. Fruits \& Vegetables.mht

2. Jones, T. C. \& Riley, D. W. (1985): "Using inventory for competitive advantage through supply chain management", International Journal of Physical Distribution and Materials Management, Vol.15, No.5,pp 16-26.

3. Fearne, A. (1996): Editorial note, Supply Chain Management, Vol.1, No. 1, pp, 3-4.

4. Simchi-Levy, D. and Simchi-Levy, £. (2003) 'Finding the Right Balance', Logistics Today, December, pp. 16-18.

5. Nassimbeni G. (1999) "Network structures and co-ordination mechanisms: a taxonomy, International Journal of Operations and Production Management, 18, (6), pp. 538554.

6. Maheshwar $\mathrm{C}$ and T.S. Chanakwa: Post harvest losses due to gaps in cold chain in India- a solution, ISHS Acta Horticulture, 712: IV International conference on Managing Quality in chain- The Integrated view on Fruits and Vegetables quality.

7. Business Line, Bangalore, 9.12.2009.

8. Financial Chronicle (Bangalore), 8.12.2009, p.8.

9. Cll in Cold Chain Summit, 2007. 